\title{
DO TELETRABALHO À SUBORDINAÇÃO ESTRUTURAL
}

\author{
TELEWORKING OF THE STRUCTURAL SUBORDINATION
}

\author{
Guilherme Domingos de Luca* \\ Alessandra Renata Rasquel Noronha**
}

Data de recebimento: $28 / 02 / 2015$

Data da aprovação: 10/06/2015

\section{RESUMO}

O presente estudo busca analisar o instituto de Direito do Trabalho denominado como "Teletrabalho", previsto no artigo $6^{\circ}$ da CLT e introduzido pelo advento da Lei 12.551/2011. O presente estudo apontará o impacto gerado por esta modificação, que introduziu os meios telemáticos e informatizados no contrato de trabalho, gerando inúmeros efeitos e consequências, além de tratar de sua clássica conceituação doutrinária. Diante disso, a problemática central do trabalho está baseada nos seguintes questionamentos: Qual o papel do teletrabalho no contrato de trabalho? O teletrabalho exerce influência na subordinação estrutural? Assim, o presente estudo tratará do entendimento conceitual do que é o teletrabalho e seu impacto nas relações laborais, apontando para a nova realidade do direito em face das tecnologias. $\mathrm{O}$ método de investigação adotado é o dedutivo, valendo-se o trabalho de comparações bibliográficas e análises de artigos e jurisprudências.

\footnotetext{
* Advogado. Mestrando em Teoria do Direito e do Estado pelo UNIVEM - Marília/ SP. Bolsista CAPES/PROSUP - Coordenação de Aperfeiçoamento de Pessoal de Nível Superior. Pós-graduando em Direito do Trabalho e Previdenciário pela PUC - Minas Gerais. Membro dos Grupos de Pesquisas NEPI - Núcleo de Estudos e Pesquisas em Direito e Internet e DIFUSO - Direitos Fundamentais Sociais, ambos cadastrados no diretório de grupos de pesquisa do CNPQ. Email: guilherme.luca@uol.com.br

** Advogada. Bacharel em Direito pelo Centro Universitário Eurípides de Marília (UNIVEM/SP). E-mail: lee_noronha@hotmail.com
} 


\title{
PALAVRAS-CHAVE
}

Teletrabalho. Subordinação estrutural. Direito do Trabalho.

\begin{abstract}
The aim of this paper is to analyze the Law Institute of Labor called "Telecommuting" or "Telework", which is provided by Article 6 of the Labor Code, introduced by the enactment of Law 12.551/2011. This study will illustrate the impact caused by this amendment and its classical doctrinal concept, which introduced telematics and computerized means in the employment contract, resulting in numerous effects and consequences. Bearing this in mind, this article's concern is represented by the following questions: What is the role of telework in the employment contract? Does telework influence the structural subordination? The main objective of this study is, therefore, based on the conceptual understanding of what telework is and its impact on labor relations, pointing to the new reality of law in the face of technology. The research method adopted is deductive, drawing on bibliographic comparison and articles' analysis and case law.
\end{abstract}

\section{KEYWORDS}

Telecommuting. Structural subordination. Labor Law. 


\section{INTRODUÇÃO}

O trabalho parte da análise de uma nova modalidade de trabalho, conhecida como teletrabalho, das suas formalidades e características, bem como da evolução do contrato de trabalho frente à flexibilização das normas trabalhistas.

O surgimento do teletrabalho é resultado do grande desenvolvimento nos meios tecnológicos, de modo que os usos dos meios de comunicação mostram-se cada vez mais essenciais para a prestação de serviços. Atualmente, esta modalidade de trabalho encontra-se prevista no Ordenamento Jurídico vigente, sendo dada, como consequência, uma nova redação ao Artigo $6^{\mathrm{a}}$ da CLT para que não restem dúvidas quanto à caracterização do vínculo empregatício. Tal assunto tem se mostrado frequente nas discussões acadêmicas de modo que o contrato de trabalho pode ser firmado de forma diversa da tradicional, sendo observados requisitos próprios. Assim, na modalidade do teletrabalho, a grande diferença encontra-se no fato de o trabalhador não executar suas atividades dentro do estabelecimento do empregador e ainda flexibilizar o requisito da subordinação jurídica.

A partir da nova redação do artigo $6^{\circ}$ da CLT, advinda da Lei 12.551/2011, há que se falar em profunda transformação nas relações trabalhistas. Assim, o presente estudo apontará o impacto gerado por essa modificação, que introduziu os meios telemáticos e informatizados no contrato de trabalho, gerando inúmeros efeitos e consequências. Ademais, o trabalho abordará ainda o que é o teletrabalho, destacando suas vantagens e desvantagens, bem como o conceito de subordinação estrutural e o impacto que o referido instituto ocasionou no contrato de trabalho.

Diante disso, a problemática central do trabalho baseia-se nos seguintes questionamentos: qual o papel do teletrabalho no contrato de trabalho e se o teletrabalho exerce influência na subordinação estrutural. É certo que o objetivo central do presente estudo é tratar do entendimento conceitual do que é o teletrabalho e seu impacto nas relações laborais, a fim de apontar para a nova realidade do direito em face das tecnologias. O método de investigação adotado é o dedutivo, valendo-se o trabalho de comparações bibliográficas e análises de artigos e jurisprudências.

\section{DA NOVA REDAÇÃO DO ARTIGO $6^{\circ}$ DA CONSOLIDAÇÃO DAS LEIS TRABALHISTAS}

É cediço que o advento da tecnologia atrelado aos novos parâmetros dos tratos sociais e também de empregos repercutiu veemente nas relações jurídicas, 
impactando na positivação normativa. É imperioso dizer que a tecnologia e os diversos avanços relacionados a ela contribuíram para o surgimento de uma nova modalidade de trabalho, a qual trouxe a possibilidade de interligação entre o empregado e o empregador pelos meios de comunicação. Assim, o empregador, nas atividades em que não necessita da presença física do empregado, passa a exercer seus poderes por outros meios não convencionais, o que afetou consubstancialmente a relação de trabalho.

A presença das novas tecnologias fez com que o empregador pudesse, de fato, exercer o seu poder de subordinação perante o empregado, pois, para a devida caracterização da relação de emprego, mesmo nessa modalidade de trabalho, é estritamente obrigatória a presença de todos os pressupostos que caracterizam o vínculo empregatício. Como apontam Fincato e Bitencourt, "o uso das tecnologias, propiciadas pelo fenômeno globalizatório, fez surgir vários tipos de relações, inclusive trabalhistas, com o surgimento de novas formas de prestação de serviços" (2014, p. 414).

Quanto à alteração da redação do Artigo $6^{\circ}$ da Consolidação das Leis Trabalhistas, foi a criação da Lei 12.551/2011 que propiciou a mudança, assegurando o trabalho efetuado fora do estabelecimento do empregador, com a presença de meios de comunicação telemáticos ou informatizados. Tal modificação na CLT reflete a modernização da norma jurídica em face da nova realidade social, absolutamente inserida nos meios tecnológicos. A antiga redação do Artigo $6^{\circ}$ da Consolidação das Leis Trabalhistas ${ }^{1}$ declarava que não havia diferenças no trabalho executado no estabelecimento do empregador ou do executado no domicílio. Naquela, apenas era reconhecido o trabalho realizado no domicílio do empregado.Porém, com as novas modificações, equiparou-se também o trabalho a distância ao trabalho realizado no estabelecimento do empregador. Com isso, a nova redação do Artigo $6^{\circ}$ da CLT, dada pela Lei 12.551/12, assim dispôs:

Art. $6^{\circ}$ Não se distingue entre o trabalho realizado no estabelecimento do empregador, o executado no domicílio do empregado e o realizado a distância, desde que estejam caracterizados os pressupostos da relação de emprego.

Parágrafo único. Os meios telemáticos e informatizados de comando, controle e supervisão se equiparam, para fins de subordinação jurídica, aos meios pessoais e diretos de comando, controle e supervisão do trabalho alheio (BRASIL, 1943).

\footnotetext{
${ }^{1}$ Art. $6^{\circ}$ Não se distingue entre o trabalho realizado no estabelecimento do empregador, o executado no domicílio do empregado, desde que estejam caracterizados os pressupostos da relação de emprego (BRASIL, 1943).
} 
As diferenças ocorreram ante a consagração da existência do trabalho a distância, sem qualquer tipo de distinção do executado no estabelecimento do empregador e o realizado no domicílio. Todavia, deverão estar presentes os pressupostos da relação de emprego para a efetiva caracterização do vínculo empregatício nesta nova modalidade de trabalho.

Para tanto, analisa-se a redação anterior do artigo objeto deste estudo, buscando a compreensão do contexto e da finalidade de sua aplicação, bem como identifica o ponto central de sua tutela. Entende-se, deste modo, que a intenção do artigo era equiparar o trabalho a domicílio [sic] ao exercido no interior do estabelecimento do empregador a fim de não descaracterizar o vínculo empregatício entre as partes por apenas inexistir controle direto e imediato por parte do superior hierárquico (VALLE, 2012, p.2).

O que foi possível notar é que o legislador, diante das diversas peculiaridades do trabalho a distância, deparou-se com a necessidade de adequar a redação do Artigo $6^{\circ}$ da CLT, com o intuito de resguardar direitos entre as partes da relação de emprego. Um ponto importante dessa nova redação foi o fato de o empregador ainda exercer o requisito da subordinação, porém por meio de formas de comunicações informatizadas, equiparando o trabalho a distância ao trabalho efetivamente prestado no próprio estabelecimento do empregador.

É certo, que, apesar da alteração da redação do artigo $6^{\circ}$ da Consolidação das Leis Trabalhistas, ainda são necessários os requisitos de toda e qualquer relação de emprego (Artigo $2^{\circ}$ e $3^{\circ}$ da CLT) destituída de direito e obrigações entre as partes. A nova redação do Artigo $6^{\circ}$ da CLT resultou na equiparação do trabalho direto realizado pelo empregado, com o trabalho a distância, onde o empregador exerce o controle direto e pessoal em relação ao empregado, uma vez que se utiliza de meios de comunicação e informatizados para exercer o requisito da subordinação.

Ressalta-se que o artigo $6^{\circ}$, da CLT, traz consigo a ideia de que se deve cumprir a subordinação jurídica, pois o empregado mesmo exercendo seus serviços fora do estabelecimento do empregador, ainda assim observará os pressupostos para a caracterização do vínculo empregatício, já que se utiliza de meios de comunicação telemáticos ou informatizados, tornando evidente, assim, a presença de subordinação na relação de emprego. Como exemplo, o empregado, ao utilizar-se de celulares, notebook ou qualquer outra tecnologia de comunicação, mesmo exercendo sua atividade laboral fora do estabelecimento do empregador, possuirá a característica de empregado, pois, trabalhando em favor daquele, está diante de uma relação de emprego. 
Assim, a lei 12.551 de 15 de dezembro de 2011, que devidamente dispõe sobre regularização de uma nova modalidade de trabalho, o teletrabalho, promoveu grandes mudanças nas relações de trabalho. Ressaltamos que tais mudanças somente ocorreram em razão do surgimento de novas tecnologias, capazes de alcançar maior proximidade entre os cidadãos, o que resultou, no ramo do Direito do Trabalho, no surgimento dessa nova forma de prestação de serviços, caracterizada pela presença das tecnologias. A respeito destas, há que se apontar também que se trata de uma necessidade que o mercado de trabalho impôs na sociedade: "O atual mundo do trabalho exige maior escolaridade, qualificação, conhecimentos atualizados e o aprendizado das novas tecnologias" (RIGOLDI; SOARES, 2014, 396).

Quanto à interpretação do Artigo 62 da CLT, a criação desse novo conceito imposto pelo advento das transformações tecnológicas trouxe questionamentos. Podese afirmar que o controle de trabalho não se modificou, pois a Lei 12.551/2011 apenas tem como enfoque a inclusão da modalidade do teletrabalho como uma relação de emprego, não modificando o conceito e apontamentos sobre o controle de jornada de trabalho. A legislação não sofreu grandes alterações e não trouxe amplo respaldo jurídico sobre a modalidade do teletrabalho, apenas incluiu um novo conceito sobre a subordinação jurídica para a configuração da relação de emprego, equiparando os meios informatizados de comunicação aos meios de controle direto do empregador.

Conclui-se, assim, que a nova redação do Artigo $6^{\circ}$ da CLT teve como grande influência a modernização da sociedade, uma vez que, ao passo que surgiram novos meios de comunicação, fez-se necessário uma nova releitura de padrões já estabelecidos em lei, como é o caso do teletrabalho. O empregado passa a utilizarse dos avanços tecnológicos e, estando diante de uma relação de emprego capaz de reconhecer o vínculo empregatício e receber todos os direitos que lhe são resguardados, essa relação equipara-se àquela do emprego comum.

\section{CONCEITO E CARACTERÍSTICAS DO TELETRABALHO}

O grande processo de modificação das tecnologias resultou no surgimento de um novo modelo de trabalho, pois, com a globalização e informatização dos meios de comunicação, foi possível a criação de novos meios de execução do trabalho, capazes de garantir ao empregador e empregador diferentes formas de se estar diante de uma relação de emprego.

Um dos novos modelos criados foi o teletrabalho, uma modalidade do trabalho à distância, que teve seu surgimento marcado pelo grande desenvolvimento tec- 
nológico ocorrido na sociedade. Fincato e Bitencourt assim definem a modalidade:

O teletrabalho, como uma nova modalidade de prestação de serviços, possibilita o trabalho à distância de forma síncrona e próxima (apesar de virtual). Assim, é possível trabalhar em qualquer lugar, de maneira subordinada, para empregador localizado em local remoto ao da prestação dos serviços (FINCATO; BITENCOURT, 2014, p. 413).

Na modalidade do teletrabalho, tendo em vista os novos meios de informação e comunicação, o empregado não mais necessita trabalhar no estabelecimento do empregador, podendo assim, exercer suas atividades fora da sede da empresa, resultando na menor concentração de empregados em um determinado lugar. Sobre isso, Garcia afirma que

O teletrabalho é uma modalidade de trabalho à distância, típica dos tempos modernos, em que o avanço tecnológico permite o labor fora do estabelecimento do empregador (normalmente na própria residência do empregado), embora mantendo o contato com este por meio de recursos eletrônicos e de informática, principalmente computador e a internet (GARCIA, 2012, p.107).

Nota-se que há a utilização dos meios de comunicação para a maioria atos exercidos pelo empregado, o qual se utiliza não apenas de computadores, mas também de todos os meios informatizados existentes na realidade atual. $\mathrm{O}$ grande enfoque é o fato de, embora o empregado estar longe das dependências do empregador, o contato ser feito e mantido em tempo real por meios capazes de transportar informações de um lugar para o outro, como é o caso dos celulares. Enquadrar-se na modalidade do teletrabalho não diz respeito a apenas executar o trabalho em seu domicílio, mas também ao fato de o trabalho ser executado em diferentes estabelecimentos. Assim é certo que o domicílio não é o único local para prestação dos serviços.

Alice Monteiro de Barros faz uma distinção entre a figura do teletrabalho com o trabalho em domicílio:

O teletrabalho distingue-se do trabalho a domicílio tradicional não só por implicar, em geral, a realização de tarefas mais complexas do que as manuais, mas também porque abrange setores diversos como: tratamento, transmissão e acumulação de informação; atividade de investigação; secretariado, consultoria, assistência técnica e auditoria; gestão de recursos, vendas 
e operações mercantis em geral; desenho, jornalismo, digitação, redação, edição, contabilidade, tradução, além da utilização de novas tecnologias, como informática e telecomunicações, afetas ao setor terciário (BARROS, 2010, p.327-328).

Ora, o trabalho a distância compreende tanto o teletrabalho quanto o trabalho em domicílio, porém não se confundem, uma vez que o teletrabalhador pode exercer suas atividades em domicílio sem, contudo, caracterizar-se dentro da relação de trabalho em domicílio. Depreende-se, assim, que a figura do teletrabalho possui particularidades que a distingue das demais modalidades, evidenciando-se o caráter inovador deste novo instituto no Ordenamento Jurídico.

Retomamos que foram as grandes transformações tecnológicas que impulsionaram o surgimento deste trabalho a distância e que, mesmo que o trabalhador exerça suas atividades fora do estabelecimento do empregador, ele não deixará de ser considerado empregado para os devidos fins legais, observando-se com isso todas as características inerentes à relação de emprego. Assim, na modalidade do teletrabalho há a presença de todos os requisitos necessários para a caracterização do vínculo empregatício. Porém, um ponto que merece destaque é o caso da subordinação jurídica, pois na modalidade do teletrabalho, esse requisito é visto de forma diferente. No teletrabalho, controle realizado pelo empregador é feito por meio de aparelhos tecnológicos, ou seja, esses aparelhos serão o meio do empregador exercer seu poder de controle e fiscalização sobre empregado. Assim, é possível notar certa particularidade sobre este requisito indispensável para caracterização do vínculo empregatício, evidenciando a grande importância dos meios de comunicação telemáticos ou informatizados nesta modalidade de trabalho.

Dessa feita, a modalidade do teletrabalho está presente, não só no Brasil, como também em outros diversos países, tratando-se de uma modalidade do trabalho a distância que possui grande relevância para as modificações ocorridas em todo o ordenamento jurídico. Revela-se, pois, que as inovações tecnológicas influenciaram a relação de trabalho, uma vez que os meios de comunicação e informação foram desenvolvidos e, atualmente, garantem ao empregado e ao empregador uma nova modalidade de trabalho, que lhe dão amparo jurídico para a efetiva prestação de serviços.

Na modalidade do teletrabalho, as grandes características encontram-se no fato de o trabalhador dispor da possibilidade de executar os serviços fora do estabelecimento do empregador, bem como a existência essencial de meios de comunicação telemáticos ou informatizados. O referido trabalho só se torna possível graças ao auxílio da Internet que é um instrumento absolutamente inserido no contexto social: 
Um fator que muito influenciou este contexto foi o espaço que a Internet passou a ocupar na sociedade. Cada vez mais ela se torna indispensável nas relações humanas, funcionando enquanto ferramenta de comunicação, trabalho e lazer (GARCIA; DE LUCA, 2012, p. 151-152).

A grande evolução ocorrida em razão do surgimento dessa nova modalidade foi capaz de modificar a maneira como se executa o trabalho e ainda, a disposição entre espaço e tempo durante a prestação de serviços.

Em relação ao pressuposto da pessoalidade, há certas indagações que merecem ser expostas. Na modalidade do teletrabalho há certa distorção dos pressupostos indispensáveis à relação de emprego, porém, mesmo que não esteja aparentemente presente, é preciso analisar, em todos os casos, a efetiva presença dos meios informatizados de comunicação durante a prestação de serviços. O teletrabalhador está sob a proteção jurídica, possuindo, assim, direitos e deveres como todo e qualquer empregado, pois ocorreu a adequação da realidade tecnológica ao meio ambiente de trabalho.

Embora não haja, na legislação, matéria capaz de dispor sobre todos os detalhes dessa modalidade de trabalho, ou seja, não há um profundo embasamento jurídico, já que se trata de uma recente forma de trabalho, há certa problemática sobre o tema do teletrabalho, pois, apesar de ter sido dada uma nova redação ao Artigo $6^{\circ}$ da CLT, não há uma forte regulamentação. Dessarte, o embasamento jurídico sobre a modalidade do teletrabalho não é aprofundado, resultando em algumas controvérsias sobre o referido tema. Assim, sob este prisma, convém notar que há a previsão nos Artigos $6^{\circ}$ e Artigo 83 da CLT e esses artigos tratam sobre o tema do teletrabalho, motivo que revela a necessidade de maior tutela jurisdicional sobre o assunto, pois trata-se de real situação jurídica existente no meio ambiente de trabalho (BARROS, 2010, p.329).

Ainda que recente, é notório que a modalidade do teletrabalho tem se expandido e, cada vez mais, encontram-se relações de trabalho com as características do teletrabalho. O teletrabalho é uma flexibilização do contrato de trabalho, haja vista o surgimento de novas tecnologias dentro do setor de comunicação e de informática. Revela-se, gradativamente, que as diversas atividades desenvolvidas na sociedade atualmente dependem da utilização de meios de comunicação telemáticos ou informatizados. A constante necessidade de o ser humano se relacionar, não apenas frente a frente, mas também pelas novas tecnologias (FARIAS; HENRIQUES; PORTO, 2011). Logo, o teletrabalho surge por razão dessa necessidade, pois o empregado passa a relacionar-se com o empregador por esses meios de comunicação e, 
com essas características, há um melhor desenvolvimento e produtividade da empresa. Ressalta-se que é possível observar algumas características próprias, as quais o fazem diferenciar do trabalho comum.

Em relação à existência efetiva dessa modalidade de trabalho, é necessário que haja, entre empregado e empregador, um acordo capaz de estabelecer quais os direitos e obrigações entre eles e ainda, como será efetivamente realizada a prestação de serviços, ou seja, qual período, qual a frequência, quais recursos serão utilizados. Sendo assim, é correto afirmar que há a devida observância dos interesses de ambas as partes desta relação de emprego (FARIAS; HENRIQUES; PORTO, 2011).

Outra característica do teletrabalho é o fato de serem estabelecidas metas ao empregado, pois este deverá executar suas atividades de forma organizada e com disciplina. O empregado, não poderá exercer suas atividades de forma irregular e como entender, é necessário que existam regras e metas a serem observadas, pois, com isso, haverá um funcionamento eficaz da prestação de serviços, onde tanto empregado quanto empregador, serão capazes de usufruir dos benefícios dessa modalidade de trabalho (OLIVEIRA; DINARTE, 2014, p. 503).

Além de disciplina e organização, é necessário que ocorra a comunicação entre a empresa e o teletrabalhador, mantendo-se o controle diretivo da empresa e a subordinação do empregado. O empregador, ao exercer o controle sobre o empregado e ao estabelecer metas para alcançar uma maior produtividade deverá realizar um planejamento das atividades do empregado para que assim consiga estabelecer seu poder de direção e alcançar uma prestação de serviços regular e capaz de garantir muito rendimento.

No caso do teletrabalho, em razão das peculiaridades quanto à forma de prestação do serviço pelo empregado e do exercício do poder de direção pelo empregador, a subordinação jurídica pode ser decorrente de meios telemáticos e informatizados de comando, controle e supervisão (GARCIA; 2012 p.108).

Assim, o empregador exercerá, conforme já mencionado, seu poder de controle e direção sobre o empregado, pelos meios de comunicação com os quais serão capazes, empregador e empregado, de estabelecer a relação de emprego.

Outro ponto a ser destacado sobre as características do teletrabalho é o fato de o empregado realizar suas atividades fora do estabelecimento do empregador, fato este que leva a melhor aproveitamento do tempo e ainda faz com que não seja necessário o deslocamento do empregado, combinando, entretanto, com o fato de 
utilizar-se de meios tecnológicos (OLIVEIRA; DINARTE, 2014, p. 503). O critério para a escolha do local da prestação de serviços também poderá ficar a critério do empregado, que optará em qual local realizará suas atividades, sendo que tal situação auxilia em um melhor aproveitamento do empregado, o qual trará benefícios não só para o empregado, como também para o empregador.

Além das características acima elencadas, é imprescindível que o empregador disponha de controle sobre o empregado, ou seja, controlar não apenas quais serviços serão prestados, como também o tempo de execução dos mesmos.

A modalidade do teletrabalho é fruto de uma evolução tecnológica em toda a sociedade, capaz de alterar normas trabalhistas, que se adequaram a realidade atual, resultando, assim, em modificações benéficas para ambas as partes da relação de emprego.

\section{VANTAGENS E DESVANTAGENS ACERCA DO TELETRABALHO}

As grandes modificações ocorridas na sociedade em razão do grande avanço das tecnologias foram as responsáveis pelo surgimento do teletrabalho, conforme já apontado. Porém, neste momento, faz-se necessário analisar quais as vantagens ou desvantagens dessa modalidade de trabalho para melhor compreender sua aplicação em nosso cotidiano. É preciso mencionar que, mesmo em se tratando de um tema que foi inserido em nosso contexto há pouco tempo, já existem inúmeras observações sobre seus pontos positivos e negativos dentro da relação de emprego.

Em princípio, destaca-se que as alterações ocorridas no meio ambiente de trabalho e as partes da relação de emprego estão amparadas por lei, podendo exercer suas atividades de forma lícita e ainda serem detentores de direitos e obrigações.

Tratando-se de uma modalidade de trabalho de extrema relevância na sociedade em seu momento atual, não poderia ser esquecido o fato de que todas essas mudanças se deram em razão da presença de meios de comunicação telemáticos ou informatizados capazes de alterar os padrões existentes e alcançar o surgimento de uma nova modalidade de trabalho (ARAÚJO, 2015). Ora, convém ressaltar, que o ser humano atualmente se vê dependente dos meios de comunicação, fato este que caracteriza grandes alterações no ordenamento jurídico, pois, como é sabida, na modalidade do teletrabalho, a utilização destes meios é imprescindível para a caracterização da relação de emprego.

Em relação ao empregador e dentre os pontos positivos para a sua atividade empresarial e os benefícios que poderão ser alcançados com a inserção desta modali- 
dade de trabalho em seu estabelecimento, o primeiro ponto abordado diz respeito aos custos que poderão ser reduzidos pelo empregador na modalidade do teletrabalho. Ora, o empregado ao exercer suas atividades fora do estabelecimento do empregador, não estará dispondo dos recursos ali presentes, como por exemplo, água, energia. Assim ao deslocar-se para outro local para a prestação de serviços o empregado não fará parte dos gastos oriundos do estabelecimento (ARAÚJO, 2015). Outro fator importante refere-se à questão do empregador não possuir a necessidade de pagamento de auxílio transporte, ou outro qualquer gasto referente ao seu deslocamento.

Ainda quanto ao deslocamento do empregado até o estabelecimento do empregador, há outros enfoques a serem observados. O primeiro trata-se do acidente de trabalho. É certo que tal situação não ocorre nessa modalidade de trabalho, uma vez que o empregado não necessita deslocar-se para a prestação de serviços, já que poderá, muitas vezes, permanecer em sua residência ou em qualquer outro lugar (ESTRADA, 2008). Assim, é certo que haverá a prevenção de ocorrência de acidentes durante o seu período de deslocamento até o estabelecimento, acarretando assim, em menos constrangimentos entre empregado e empregador, bem como garantia de saúde e proteção e integridade física do trabalhador. Além disso, insta observar que em casos de grandes centros o empregado deixará de enfrentar o trânsito caótico, fato este que será capaz de influenciar em sua produtividade, tendo em vista haver a diminuição do estresse decorrente desta situação. Neste contexto, revela-se que o empregado não estará sobrecarregado para o exercício de suas atividades.

Outro ponto que merece destaque, diz respeito ao fato de se evitar a emissão de gases poluentes na atmosfera, pois o empregado, não necessitando deslocarse até a empresa, não utilizará de qualquer meio de transporte, o que resultará em melhores resultados para o meio ambiente (ARAÚJO, 2015).

Em todos os aspectos, o empregador passará a receber um trabalho mais produtivo, pois o empregado, por estar diante de menos pressão, acabará elevando seu caráter produtivo rendendo bons frutos para o empregador. Mais um fator importante é a diminuição de faltas do empregado, o que, além de melhorar o relacionamento entre as partes desta relação de emprego, pode proporcionar aumento de lucro da empresa, resultando assim em uma maior produtividade, já que não existirão motivos que o impeçam de se deslocar até a empresa.

Assim, notam-se vantagens para o empregador, bem como inúmeros benefícios advindos da relação de emprego na modalidade do teletrabalho também para o empregado. As vantagens mencionadas caracterizam um melhor desenvolvimento da atividade da empresa, além de auxiliarem o empregado, uma vez que proporcio- 
na melhora em sua qualidade de vida, garantindo emprego para pessoas que teriam dificuldades para consegui-lo. Nota-se o grande avanço na sociedade, pois tal fato poderá diminuir as diferenças e desigualdades entre os cidadãos. Neste contexto, pode-se observar que através da modalidade do teletrabalho há um aumento de oportunidades para os cidadãos, ou seja, oportunidade de alcançar uma vida digna através do trabalho, e ainda, dar dignidade e segurança a sua família.

Já em relação às desvantagens da modalidade do teletrabalho, primeiramente, deve-se mencionar o fato de o empregador necessitar de investimentos em meios de comunicação telemáticos ou informatizados. Em razão de ser obrigatória a presença de equipamentos de tecnologia para a caracterização desta modalidade de trabalho, é clara a obrigatoriedade da presença dos mesmos, os quais serão adquiridos pelo empregador, para que o empregado possa de fato exercer suas atividades como teletrabalhador (SILVA, 2012, p. 34).

Há ainda outro ponto importante que precisa ser mencionado: o empregador, ao permanecer em sua residência para o labor, ou ainda, em qualquer outro estabelecimento, estará, pois, isolando-se dos trabalhadores a ele equiparados, fazendo-o perder as relações sociais durante a prestação de serviços, o que poderá, eventualmente, prejudicar sua produtividade.

Alice Monteiro de Barros preleciona:

(...) Ora, é sabido que o trabalho realizado no estabelecimento do empregador permite, em muitas funções, o contato com colegas, propiciando conversas amenas, troca de ideias e discussão de problemas pessoas e familiares, em clima de interação profissional e emocional (2010, p.329).

Outra desvantagem da modalidade do teletrabalho refere-se à questão de o empregado, exercendo suas atividades em sua residência, não conseguir separar o trabalho de sua família. Ou seja, o empregado passa a relacionar-se com sua família durante a execução de suas atividades, comprometendo, assim, sua concentração, o que também poderá afetar sua produtividade. Há também, casos em que o trabalhador poderá se colocar em situações conflitantes com seus familiares durante a prestação de serviços (SILVA, 2012, p. 35). O labor a distância compromete ainda, o poder diretivo do empregador, o qual, por não estar em contato direto com o empregado, não conseguirá exercer sobre ele o controle e a fiscalização de suas atividades.

Em relação ao tempo de execução de suas atividades, há o enfoque ainda em relação à disposição do tempo pelo teletrabalhador. O que é possível notar, muitas vezes, é que o empregado poderá exceder o tempo de serviço, pois perde o controle 
do tempo já que exerce suas atividades em sua residência, o que, consequentemente, acarretará uma prestação de serviço árdua e com chances de ser tornar falha.

Outra desvantagem refere-se ao empregado, pois, por estar em contato direto com meios telemáticos e informatizados, acaba por comprometer sua saúde, ou seja, problemas visuais que poderão acarretar prejuízos futuros em razão da utilização, em excesso, destes equipamentos, por utilizá-los diariamente (ARAÚJO, 2015).

Conclui-se, portanto, que estamos diante de uma relação de trabalho que traz não apenas benefícios, mas também situações em que o poderá haver certo prejuízo. Por outro lado, tais desvantagens podem ser sanadas no caso de o empregado e empregador estabelecerem os parâmetros desta relação de emprego.

\section{O TELETRABALHO E A SUBORDINAÇÃO ESTRUTURAL}

O instituto da subordinação jurídica é de extrema relevância para o Direito do Trabalho, afinal, como é sabido, é um pressuposto essencial para a caracterização da relação de emprego.

Segundo Maurício Godinho Delgado subordinação é:

(...) A subordinação classifica-se, inquestionavelmente, como um fenômeno jurídico, derivado do contrato estabelecido entre trabalhador e tomador de serviços, pelo qual o primeiro acolhe o direcionamento objetivo do segundo sobre a forma de efetuação da prestação do trabalho (2011, p.292).

Entretanto com as mudanças ocorridas na sociedade, sobretudo, o avanço da tecnologia e o surgimento de novos conceitos, tornou-se necessário ampliar o conceito de subordinação e ainda redefini-lo a fim de proteger a relação de traba1ho. Nesse sentido, em relação à modalidade de teletrabalho, é certo que ocorreu uma flexibilização conceitual de subordinação, pois, nesta modalidade de trabalho, o empregador não mantém contato visual e direto com o empregado, não exercendo assim, a clássica subordinação. Assim pode ser classificada:

Clássica é a subordinação consistente na situação jurídica derivada do contrato de trabalho, pela qual o trabalhador compromete-se a acolher o poder de direção empresarial no tocante ao modo de realização de sua prestação laborativa. Manifesta-se pela intensidade de ordens do tomador de serviços sobre o respectivo trabalhador (DELGADO, 2011, p.293). 
Ora, a subordinação estrutural difere da subordinação clássica, pois a primeira trata-se de uma forma de subordinação à distância, em que o empregado exerce as suas atividades longe do estabelecimento do empregador, porém, ainda assim, é caracterizado como empregado, tendo em vista fazer parte da organização estrutural da empresa. Nesse contexto, o vínculo empregatício não será considerado ausente, pois ainda assim será caracterizada a subordinação, porém em um contexto diferente.

A teoria da subordinação estrutural viria para complementar a ideia clássica de subordinação, não se abandonando os critérios tradicionais, porém ampliando a incidência da proteção estatal quando da aplicação do conceito de subordinação estrutural (FRAGA, 2011, p.2).

Na subordinação estrutural, o que caracterizará efetivamente a subordinação é o fato de o trabalhador estar inserido na estrutura organizacional da empresa, sendo ele um prestador de serviços, sem, contudo, necessitar do poder de direção e controle do empregador. Esse novo conceito surgiu diante da necessidade de ampliar os diretos do trabalhador, assegurando-lhe o vínculo empregatício e a caracterização da relação de emprego, bastando apenas a sua integração na estrutura da empresa tomadora de serviços (DELGADO, 2011, p. 294).

Com isso, nota-se que na modalidade do teletrabalho, o conceito de subordinação estrutural é necessário para dar amparo legal a esta nova relação de emprego, além da capacidade de tutelar os direitos do trabalhador. Ora, muitas vezes é notória a dificuldade de identificação do requisito da subordinação na modalidade do teletrabalho, porém, com o conceito de subordinação estrutural esta dificuldade pode diminuir, afinal, bastará apenas que o empregado esteja inserido na atividade organizacional da empresa para a caracterização do vínculo empregatício.

Assim, é certo que a subordinação decorrente do poder de direção não deixará de ser caracterizada, contudo, quando este poder for de difícil identificação, poderá ocorrer a aplicação da subordinação estrutural, sendo necessário apenas que o empregado faça parte do quadro produtivo da empresa, em sua estrutura e organização.

SUBORDINAÇÃO ESTRUTURAL. COMPROVAÇÃO. Comprovado que o empregado executou serviços essenciais à atividade fim da empresa, isto é, que se inserem na sua atividade econômica, resta configurada a subordinação estrutural ou integrativa, já que integra o processo produtivo e a dinâmica estrutural de funcionamento da empresa ou do tomador de serviços. (TRT-1 - RO: 1193620125010244 RJ , Relator: Fernando Antonio 
Zorzenon da Silva, Data de Julgamento: 31/07/2013, Segunda Turma, Data de Publicação: 07-08-2013) (BRASIL, 2013)

Com o conceito de subordinação estrutural, surgiu a capacidade de o trabalhador, exercendo suas atividades na condição de teletrabalhador, enquadrar-se como empregado, resguardando-lhe assim os direitos sociais advindos da relação de emprego.

Assim, é nítida a flexibilização do conceito de subordinação, pois na relação de emprego não é mais fundamental o controle direto do empregador sob o empregado. O empregado pode exercer suas atividades e atribuições sob o controle do empregador, ainda que indiretamente, como é o caso da subordinação estrutural na modalidade do teletrabalho. O conceito de subordinação estrutural é resultado do grande avanço das novas formas de trabalho e ainda do desenvolvimento econômico e tecnológico ocorrido em toda a sociedade.

Logo, com a inserção desse conceito de subordinação estrutural, o trabalhador que exerce suas atividades por novas formas de trabalho, também será considerado empregado para os devidos fins legais, resultando na ampliação de conceitos importantes do Direito do Trabalho. Com a subordinação estrutural o empregador passará a ordenar as atividades de forma diferente, o seu poder de controle e direção será direcionado ao alcance dos resultados do empregado e não os meios que ele utilizou-se para a execução da prestação de serviços. Ou seja, o empregador verificará o rendimento daquele determinado trabalhador, a fim de verificar os objetivos alcançados pelo mesmo.

O grande enfoque na subordinação estrutural é o fato de o trabalhador estar inserido na organização estrutural da empresa e não caracterizado como trabalhador autônomo, uma vez que há presença do requisito da subordinação. $\mathrm{O}$ empregado não será responsável por organizar suas próprias atividades, já que tal função será de responsabilidade do empregador. No tocante à prestação de serviços, possuirá caráter essencial para o desenvolvimento do estabelecimento do empregador, o que efetivamente, caracterizará a relação de emprego com a presença da subordinação estrutural.

Em outras palavras, a subordinação, em sua dimensão estrutural ou integrativa, faz-se presente, quando a prestação de trabalho integra as atividades exercidas pela empresa, e o trabalhador não possui uma organização empresarial própria, não assume verdadeiramente riscos de perdas ou de ganhos e não é proprietário dos frutos do seu trabalho, que pertencem, 
originariamente, à organização produtiva alheia para a qual presta a sua atividade (REIS, 2012).

Desse modo, estando o empregado inserido nas atividades da empresa, sem se responsabilizar por riscos pertencentes à atividade empresarial, nem tampouco, ser proprietário, será necessário que ele faça parte da estrutura empresarial de determinada empresa, bem como que sua atividade seja fundamental dentro da relação de emprego para que se caracterize o vínculo empregatício. Nota-se, então, que o grande avanço e evolução do conceito de subordinação são de enorme importância para o Direito do Trabalho, especificamente, para o empregado, que poderá ter seus direitos garantidos mesmo estando inserido em uma relação de emprego diferente da tradicional.

Sendo assim, é relevante observar que o Direito do Trabalho está em constante transformação, e ainda é capaz de adequar-se a realidade e evoluir os conceitos e parâmetros, a fim de alcançar a segurança jurídica tanto para o empregado quanto para o empregador.

E assim, a subordinação, considerada um dos mais importantes pressupostos da relação de emprego, acaba por se tornar mais flexível, admitindo-se novas interpretações e novas regras para a observação do vínculo empregatício, não deixando, entretanto, de lado a necessidade de organização e critério para o ordenamento jurídico atual, bem como, todas as diferentes relações de emprego oriundas do cotidiano.

\section{CONCLUSÃO}

Sem dúvida alguma, o teletrabalho é o reflexo do impacto das tecnologias no contrato de trabalho. Essa modalidade laboral surgiu por meio da modificação e flexibilização de normas do Ordenamento Jurídico inserida com a nova redação dada ao Artigo $6^{\circ}$ da CLT e que, atualmente, tem se mostrado uma modalidade de trabalho bastante influente. Nessa ótica, o empregado, ainda que fora do estabelecimento do empregador, poderá ter caracterizado o vínculo empregatício, sendo que para isso, utilizam-se dos meios de comunicação, garantindo-se a observância dos pressupostos da relação de emprego, quais sejam: subordinação, habitualidade, onerosidade, pessoalidade e pessoa física.

No que tange ao teletrabalho e à subordinação, o trabalhador encontra-se em situação não tradicional, uma vez que está fora do estabelecimento do empregador, porém, ainda encontra-se em estado de subordinação, pois possui dependência e 
obedece a ordens impostas pelo empregador. Contudo, ainda que o requisito da subordinação seja apresentado de forma diferente nesta modalidade de trabalho, não há dúvidas de que há a presença do mesmo, tendo em vista que se caracteriza o vínculo empregatício pelos meios de comunicação ou informatizados.

A referida modalidade de trabalho vem se expandindo cada vez mais, pois a sociedade desenvolve-se a cada dia e as tecnologias se apresentam cada vez mais evoluídas, fato este que enseja em um grande desenvolvimento e evolução do Ordenamento Jurídico. Ainda que o empregado exerça suas atividades em sua residência, por exemplo, poderá alcançar todas as metas que lhe são passadas e estará trabalhando de forma intelectual e desenvolvendo cada vez mais suas ideias. $\mathrm{Ou}$ seja, irá trabalhar a mente e irá aprimorar seus conhecimentos. Portanto, é certo que, embora o empregado esteja fora do estabelecimento do empregador, exercerá suas atividades de forma subordinada e respeitando todos os deveres que lhe são passados e, sobretudo, estará trabalhando.

Outro grande fator importante apresentado, diz respeito aos pontos positivos e negativos desta modalidade de trabalho, porque, muito embora existam novas normas que a regulamente, existem pontos positivos e negativos que fazem com que se analisem quais são as vantagens e desvantagens dessa modalidade de trabalho, tanto para o empregado quanto para o empregador.

Desse modo, ainda que se trate de uma modalidade de trabalho bastante recente em nossa sociedade, é de grande valia para todos os cidadãos que integram uma relação de emprego, afinal, os meios de comunicação estão cada vez mais evoluindo e trazendo novos métodos de utilização, resultando assim, no desenvolvimento da coletividade.

\section{REFERÊNCIAS}

ARAÚJO, Patrícia. Teletrabalho: Que vantagens e desvantagens. Disponível em: $<$ https:// www.portal-gestao.com/item/6013-teletrabalho-que-vantagens-e-desvantagens?.html>. Acesso em: 15 fev. 2015.

BARROS, Alice Monteiro de. Curso de Direito do Trabalho. 6.Ed. rev. e atual. São Paulo: LTR, 2010. 
BRASIL. Decreto-lei n. 5.452, de 1 de maio de 1943. Consolidação das Leis do Trabalho. Disponível em: <http://www.planalto.gov.br/ccivil_03/decreto-lei/del5452.htm>. Acesso em: 20 fev. 2015.

.TRIBUNALREGIONALDOTRABALHODA $1{ }^{\mathrm{a}}$ REGIÃO.RO: 1193620125010244 RJ. Relator: Fernando Antonio Zorzenon da Silva, Data de Julgamento: 31 set. 2013. Segunda Turma, Data de Publicação: 07-08-2013. Disponível em: <www.trt1.jus.br>. Acesso em: 20 jan. 2015.

DELGADO, Maurício Godinho. Curso de Direito do Trabalho. 10. ed. São Paulo: LTR, 2011.

ESTRADA, Manuel Martin Pino. Definições e vantagens do teletrabalho. Publicado em: 27 jun. 2008. Publicado em: <https://comunicacaodemocratica.wordpress.com/2008/06/27/ teletrabalho-definicoes-e-vantagens/>. Acesso em: 13 fev. 2015.

FARIAS, Lucas Serrano. HENRIQUES, Rayssa Vieira; PORTO, Vanessa de Araújo. Teletrabalho no Brasil: Um ensaio sobre a modalidade de trabalho dos novos tempos. In Amatra 13. Disponível em: <www.amatra13.org.br/new/conteudo.php?pg=publicacao\&puTipo=6\&puCodigo $=2249>$. Acesso em: 20 fev. 2015.

FINCATO, Denise Pires; BITENCOURT, Manoela de. Teletrabalho transnacional: Tributação da renda dos teletrabalhadores no plano internacional. In: Direito do trabalho IV organização CONPEDI/UFPB; coordenadores: Paulla Christianne da Costa Newton, Daniela Mesquita Leutchuk de Cademart. 1ed.Florianópolis: CONPEDI, 2014.

FRAGA, Cristiano. Subordinação Estrutural: um novo paradigma para as relações de emprego.2011. Disponível em: <http://www3.pucrs.br/pucrs/files/uni/poa/direito/graduacao/ tcc/tcc2/trabalhos2011_1/cristiano_fraga.pdf> Acesso em: 09 jan. 2015.

GARCIA, Bruna Pinotti; DE LUCA, Guilherme Domingos. Democracia digital: os rumos da regulamentação legislativa no ordenamento jurídico brasileiro. Democracia Digital e Governo Eletrônico. Democracia Digital e Governo Eletrônico, v. 6, p. 146-179, 2012.

GARCIA, Gustavo Felipe Barbosa. Manual de Direito do Trabalho. 5.Ed.rev. e atual.. Rio de Janeiro: Forense; São Paulo: Método, 2012.

OLIVEIRA, Gislaine Ferreira; DINARTE, Priscila Valduga. É tudo trabalho? Análise comparada do tratamento jurídico do teletrabalho na União Europeia e no Brasil. In: organização CONPEDI/UFSC; coordenadores: Mirta Gladys Lerena Manzo de Misailidis, Lucas Gonçalves da Silva, Maria Rosaria Barbato.. (Org.). Direito do trabalho. 1ed.Florianópolis: CONPEDI, 2014. 
REIS, Sérgio Cabral dos. Juiz escreve artigo sobre subordinação estrutural. 2012. Disponível em: <http://www.trt13.jus.br/informe-se/noticias/2012/02/juiz-escreve-artigo-sobre-subordinaassapso-estrutural>Acesso em: 22 jan. 2015.

RIGOLDI, Vivianne; SOARES, Andréa Antico. O Direito ao trabalho digno na perspectiva da educação especial inclusiva. In: Direito do trabalho II [Recurso eletrônico on-line] organização CONPEDI/UFPB; coordenadores: Maria Rosaria Barbato, Luciana Aboim Machado Gonçalves da Silva, Marconi do O. Catão. - Florianópolis : CONPEDI, 2014.

SILVA, Joseane Maira. Direito do trabalho e direitos autorais: investigação acerca dos possíveis confltos de titularidade decorrente do desenvolvimento de software por empregado contratado no regime de teletrabalho. Disponível em: <www.bc.furb.br/docs/ MO/2012/351671_1_1.PDF>. Acesso em: 12 fev. 2015.

VALLE, Fernanda Dalla. Considerações sobre a alteração da redação do Artigo $6^{\circ}$ da CLT impostas pela Lei 12.551/2011. 2012. Disponível em: $<$ http://www.egov.ufsc.br/portal/ sites/default/files/consideracoes_sobre_a_alteracao_da_redacao_do_artigo_6o_da_clt_impostas_pela_lei_12.551_2011.pdf> Acesso em: 25 fev. 2015. 